\title{
INFLUENCE OF THE TEETH NUMBER ON THE GEAR MODULE VALUE AND LOAD CAPACITY OF GEAR PAIR IN UNIVERSAL HELICAL GEAR DRIVES
}

UDC: 621.833

Original scientific paper

https://doi.org/10.18485/aeletters.2018.3.1.4

\author{
Milan Rackov ${ }^{1}$, Mirko Blagojević ${ }^{2}$, Siniša Kuzmanovići ${ }^{1}$, Miloš Matejić², Ivan Kneževićc ${ }^{1}$, Maja \\ Čavić $^{1}$
}

${ }^{1}$ University of Novi Sad, Faculty of Technical Sciences, Trg Dositeja Obradovića 6, 21000 Novi Sad, Serbia

${ }^{2}$ University of Kragujevac, Faculty of Engineering, Sestre Janjic 6, 34000 Kragujevac, Serbia

\begin{abstract}
:
The basic parameters of the universal gear drives, except the axis height, are not defined by the standard, so the manufacturers of universal gear reducers can define them in their way. Most of the manufacturers followed the parameter values of universal gear reducers of leading world producers in order to ensure their interchangeability and the better positioning of their gear units at the market. This paper deals with the analysis of the influence of the gear pair teeth number on the size of the module, as well as on the load carrying capacity of single-stage universal gear units. For defined gear ratio values, different combinations of teeth number of pinion and driven gear were selected. Further, it was made calculation of the basic geometric dimensions of the gear pair, as well as the load capacity.
\end{abstract}

ARTICLE HISTORY Received 10.01.2018

Accepted 28.02.2018

Available 15.03.2018

\section{INTRODUCTION}

Axis heights of universal gear reducers are defined according to the standard row $\mathrm{R} 20(1 ; 1,12 ; 1,25 ; 1,4$; 1,$6 ; 1,8 ; 2 ; 2,24 ; 2,5 ; 2,8 ; 3,15 ; 3,55 ; 4 ; 4,5 ; 5 ; 5,6$; $6,3 ; 7,1 ; 8 ; 9 ; 10)$. Since this row is very dense, for a while manufacturers of universal gear reducer produced reducers with axis height from a standard row R10 $(1 ; 1,25 ; 1,6 ; 2 ; 2,5 ; 3,15 ; 4 ; 5 ; 6,3 ; 8 ; 10)$. But soon they increased axis heights in order to have larger dimensions to increase gear ratio, and now reducers are produced with axis height in a standard row R20/2 [1,2]. However, in the area of the most used gearbox sizes, some manufacturers produce gear units with the axis heights in a row R20. Thus, today combined row is practically used. Defining the row $\mathrm{R} 20 / 2$, which means growth factor of height is $q_{1}$ $=1.25$, it follows that growth factor of torque is $q_{\mathrm{T}}=$ $\left(q_{1}\right)^{3}=2$. This practically defines the row of output torques (R20/3 or R40/6), which is followed by almost all manufacturers of gear drives. On the basis of the axis height and the output torque, particular gear ratio values of the universal gear reducer are also defined [3-7]. However, for each value of gear ratio manufacturers specially define the load capacity, in order to use the gear unit in the most rational way (it is important to adopt as higher output torque as possible for each gear ratio) [1-3]. Of course, it should take into account the strength of all components, shafts, bearings, keys.

\section{PROBLEM DESCRIPTION}

The gear ratio of the gearbox depends on the adopted concept of the gear reducer family. Therefore, gear reducers can be manufactured in separate housing only for single-stage, two-stage, three-stage and four-stage gear unit. Such an approach is extremely expensive and nobody uses it. Generally, single-stage gear units are produced in a separate housing. However, due to lower demand for these reducers, there are manufacturers which do not produce single-stage gearbox at all, since they consider that single-stage gear units are not cost-effective. There are manufacturers who produce two-stage gearboxes in a special housing for two-stage gear units and three-stage gearboxes produce by adding one-stage gear unit to this 
special two-stage unit [4-6]. Most of manufacturers produce universal housing for two- and three-stage reducers, but this kind of two-stage gear unit is more expensive. Therefore, in this way, two- and three-stage gearboxes are produced in the same housing, with the same output gear pair and the same output shaft and bearings. According to this, it follows that the output nominal torque of twoand three-stage gearbox is the same. Since the output gear pair is much more expensive than the input (first) or the second gear pair, the number of different output gear pairs is reduced to a minimum (one or two gear pairs) and that the number of input gear pairs is increased in order to achieve different values of gear ratio within the first gear pair. These same first gear pairs are also used within singlestage gear units. If it should provide the gear ratio values within the standard row R20 for a singlestage gear drive, it should have a lot of first gear

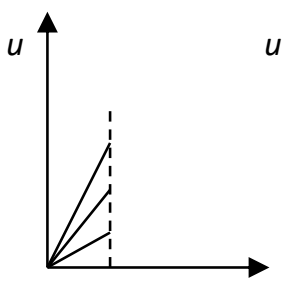

$1 x$

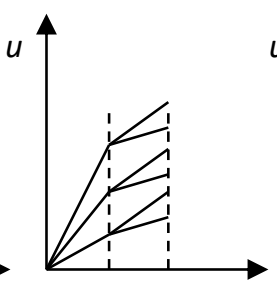

$1 \times 2 x$

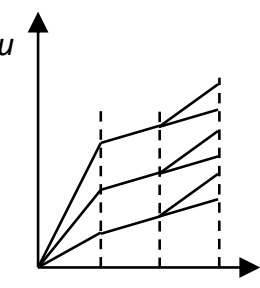

$1 x(2 x) 3 x$ a) pairs, and especially a lot of pinions (with different hole diameters in order to fit different sizes of electric motors). This production is more expensive, so some manufacturers offer gear ratio values of single-stage gearboxes within standard row R10. With two output gear pairs they provide gear ratio values of two- and three-stage gearbox within the standard row R20 (Fig.1). Nevertheless, there are manufacturers which offer gear ratio within the row R20 for single-stage gear units. Today, the second approach is considered to be more justified, since it is possible to provide all gear ratio values with a small number of expensive gears. Also, it is possible to mount different requirements of the gear ratio and thus provide their faster delivery. It is considered today that it is necessary to deliver a gear reducer to the customer as soon as possible, usually within 72 hours.

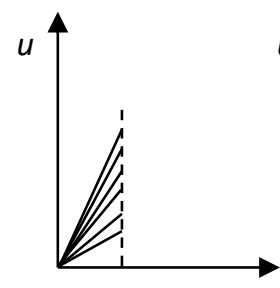

$1 x$

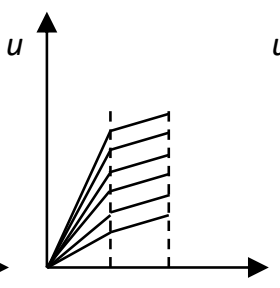

$1 \times 2 x$

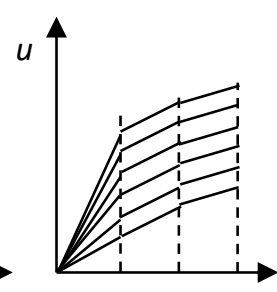

$1 \times 2 x 3 x$ b)

Fig.1. Performing of gear ratio for single-stage (1), two-stage (2) and three-stage (3) universal gear units;

(a) first gear pair is performed with gear ratio in standard row R10 and (b) first gear pair is performed with gear ratio in standard row R20

Of course, the goal is to achieve as high as possible gear ratio within each number of gear stages. Therefore, most manufacturers of gear reducers use special reducer motor which has shaft with smaller diameter than standard IEC electric motor. This allows the installation of smaller gears.
Also, special reducer motor can have a hole in the free end of the shaft where small pinions are pressed, so gear ratio can have high values (Fig.2-1). Although, there are manufacturers which use standard IEC electric motor, but also achieve relatively high gear ratio (Fig.2-2).

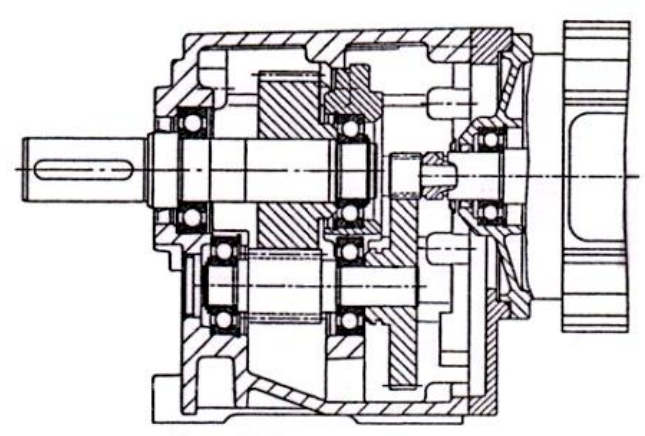

1

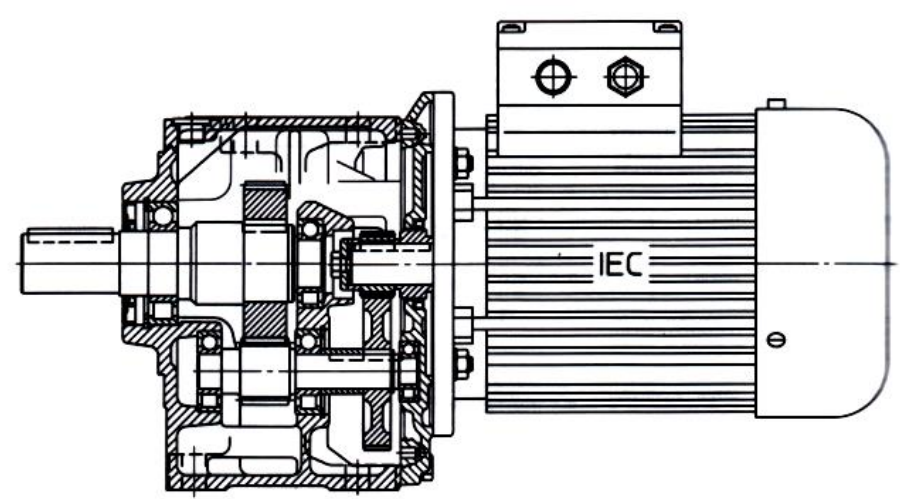

2

Fig.2. Gearmotor with special reducer motor Lenze (1) and gearmotor with standard electric motor ROSSI $(2)[7,8]$ 
The great advantage of special reducer motors is that they have stronger bearings, which allow supporting of large radial and axial forces occurring on the pinion. Sealing problem is better and seriously solved for special motors, so there is no possibility of leaking oil from the gearbox into the electric motor housing. Additionally, these special electric motors are made with smaller flanges, making the gearmotor much more compact.

Adopted concept of the housing with the common output gear pair for two- and three-stage solution allows the use of first gear pair with smaller loadability in a three-stage variant to rationally utilize the first pair (Fig.3). This first pair is from the first smaller size of a two-stage gearbox. Otherwise, the first pair would be oversized in the three-stage variant. The load carrying capacity of the first gear pair is determined on the basis of the nominal output torque and the lowest gear ratio of the second pair, in the case of two-stage gearbox; and respectively, on the basis of the nominal output torque and the lowest gear ratio of the second and third pair of three-stage gearbox $[1,3]$.

This paper defines the highest value of the gear ratio depending on the available space and it makes the variation of the modules for adopted helical angle in order to adopt the most favorable gear reducer solution.

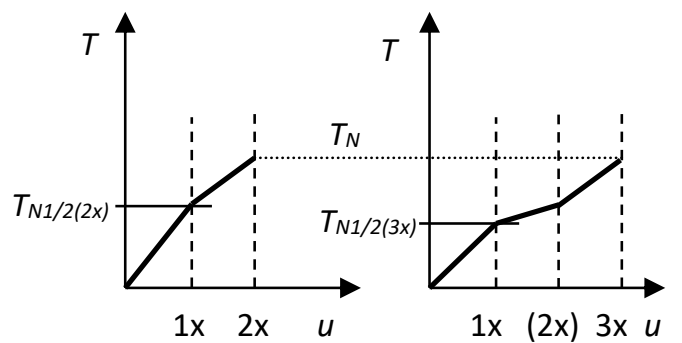

Fig.3. The way of performing output torque for twostage (1) and three-stage (2) gear reducer

\section{EXAMPLE}

For example, if single-stage gear reducer is considered for the axis height of $100 \mathrm{~mm}$, it can be concluded that many manufacturers (Table 1, 2 and 3) adopt a calculation output torque value of approx $400 \mathrm{Nm}$. However, there are manufacturers who adopt higher values of nominal torque, but they have lower gear ratios, and vice versa.

It is evident that within the available space inside the housing, i.e. for the adopted central distance and the overall dimensions, manufacturers succeed to obtain relatively high gear ratio and large load carrying capacities.

Table 1. Nominal output torque values of single-stage gear units of manufacturer SEW for particular values of the gear ratio for different axis heights and central distances [4]

\begin{tabular}{|c|c|c|c|c|c|c|c|c|c|c|c|c|c|c|c|c|}
\hline \multicolumn{17}{|c|}{ SEW, RX87, $h=100 \mathrm{~mm}, a=93,5 \mathrm{~mm}$} \\
\hline$u$ & 8.65 & 7.63 & 7.20 & 6.45 & 5.56 & 5.07 & 4.50 & 3.78 & 3.48 & 3.09 & 2.76 & 2.48 & 2.15 & 1.93 & 1.60 & 1.39 \\
\hline$T_{N 2}$ & 139 & 149 & 140 & 192 & 225 & 250 & 290 & 305 & 405 & 405 & 405 & 405 & 385 & 355 & 315 & 290 \\
\hline
\end{tabular}

Table 2. Nominal output torque values of single-stage gear units of manufacturer NORD for particular values of the gear ratio for different axis heights and central distances [5]

\begin{tabular}{|c|c|c|c|c|c|c|c|c|c|c|c|c|c|c|}
\hline \multicolumn{10}{|c|}{ NORD, SK51E, $\boldsymbol{h}=\mathbf{1 1 2} \mathbf{~ m m}, \boldsymbol{a}=\mathbf{1 0 6} \mathbf{~ m m}$} \\
\hline $\boldsymbol{u}$ & 13.27 & 9.09 & 6.82 & 5.50 & 4.04 & 3.31 & 2.86 & 2.5 & 2.06 & 1.82 & 1.64 & 1.52 & 1.44 & 1.24 \\
\hline $\boldsymbol{T}_{\boldsymbol{N} \mathbf{2}}$ & 290 & 320 & 400 & 220 & 410 & 492 & 456 & 426 & 382 & 341 & 325 & 310 & 305 & 275 \\
\hline
\end{tabular}

Table 3. Nominal output torque values of single-stage gear units of manufacturer SIEMENS for particular values of the gear ratio for different axis heights and central distances [6]

\begin{tabular}{|c|c|c|c|c|c|c|c|c|c|c|c|c|c|c|c|c|c|}
\hline \multicolumn{10}{|c|}{ SIEMENS, E88, $\boldsymbol{h}=\mathbf{1 0 0} \mathbf{~} \mathbf{m m}, \boldsymbol{a}=\mathbf{9 9} \mathbf{~ \mathbf { m }}$} \\
\hline $\boldsymbol{u}$ & 10.33 & 9.46 & 8.42 & 7.69 & 7.07 & 6.53 & 6.06 & 5.65 & 5.11 & 4.70 & 4.23 & 3.90 & 3.30 & 2.88 & 2.45 & 2.09 & 1.71 \\
\hline $\boldsymbol{T}_{\boldsymbol{N} \mathbf{2}}$ & 230 & 210 & 245 & 245 & 290 & 300 & 280 & 320 & 370 & 385 & 400 & 385 & 450 & 435 & 420 & 420 & 365 \\
\hline
\end{tabular}

Especially, it should be noted that today the values of gear ratio of single-stage gear units are adopted from the standard row R20. In the case of integer number, the teeth number of gear wheel is usually reduced by one to prevent the constant contact of the same teeth. Nowadays, eight teeth is usually adopted as the smallest number of teeth of pinion, since now the most of manufacturers of gear reducers have the technology for producing such kind of gears. Also, the distance between the outside diameter of the driven gear and the gear unit housing is reduced to approx. 2-3 mm. Also, for this axial height of $100 \mathrm{~mm}$, the thickness of the wall housing between the driven gear and the floor is reduced from $6 \mathrm{~mm}$ to only $3-4 \mathrm{~mm}$, in order to allow the installation of larger driven gears.

In this case, only the first gear pair, used for single-, two-, three-and multi-stages gearbox, will 
be analyzed. The diameter of the pinion is defined by preliminary calculation according to the equation defined by the standard [9]:

$$
d_{1}=850 \sqrt[3]{\frac{T_{1} K_{A} S_{H \min }^{2}}{\psi_{b / d} \sigma_{H \lim }^{2}} \frac{u+1}{u}}
$$

where:

$\mathrm{T}_{1}$ - torque on the pinion calculated according $T_{1}=T_{N 2} / u_{1 / 2}$. In this analyze, it is calculated as

$$
T_{1}=\frac{T_{N 2}}{u_{1 / 2}}=\frac{200}{10}=20 \mathrm{Nm}
$$

Output nominal torque for universal gear units is defined by corresponding sizes of single-stage gear units. In this case, torque $T_{N 2}=200 \mathrm{Nm}$ will be adopted for this gear ratio, similar as the most other gear units manufacturers (Tables 1, 2 and 3). Standard value $u_{1 / 2}=10$ is adopted as the value of the gear ratio, in this case.

$K_{A}-$ impact factor; it is adopted that $K_{A}=1.0$ for universal gear units, but all operation unbalances are taken into account when selecting the size of the gear unit through the service factor $\left(f_{B}\right)$ [9].

$S_{H \text { min }}-$ minimal value of safety factor. It is supposed by standard that its value is $S_{H \min }=1.2$, although it is usually enough to have a value of 1 or something above it for universal gear units [9].

$u$-gear ratio for calculated gear pair; $u_{1 / 2}=10$ is adopted as the value of the gear ratio. $\psi_{\mathrm{b} / \mathrm{d}}-$ the ratio of the width and pinion diameter; it is adopted that $\psi_{\mathrm{b} / \mathrm{d}}=1$.

$\sigma_{\text {Hlim }}$ - permitted dynamic contact stress; for carburizing steel $16 \mathrm{MnCr} 5$ it is $\sigma_{\text {Hlim }}=1470 \mathrm{~N} / \mathrm{mm}^{2}$.

Calculated value of pitched diameter is $d_{1}=18.43 \mathrm{~mm}$. Different modules and different load carrying capacities of the gear pair are obtained for different pinion teeth numbers for its constant diameter and constant helical angle (Table 4) [9-11].

If the helical angle is $30^{\circ}$ and pinion teeth number is 8 , it follows that the value of module can be calculated as $[9,10]$ :

$$
m_{n 1 / 2}=\frac{d_{1} \cos \beta_{1 / 2}}{z_{1}}=\frac{18.43 \cdot \cos 30^{\circ}}{8}=2.05 \mathrm{~mm} \mathrm{(3)}
$$

On the basis of this, it is adopted the standard value of module $m_{n 1 / 2}=2 \mathrm{~mm}$. For teeth numbers of other gear pairs, the values are given in Table 4.

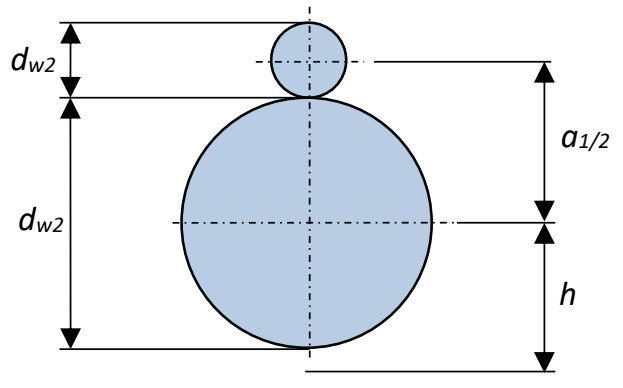

Fig. 4. Characteristic dimensions of gears and gearbox housing

\begin{tabular}{|c|c|c|c|c|c|c|c|c|c|}
\hline$u$ & $z_{1}$ & $z_{2}$ & $u_{r}$ & $\begin{array}{c}B_{1 / 2} \\
{\left[{ }^{\circ}\right]}\end{array}$ & $\begin{array}{c}m_{n 1 / 2 \text { calc }} \\
{[\mathrm{mm}]}\end{array}$ & $\begin{array}{c}m_{\mathrm{n} 1 / 2 \text { stan }} \\
{[\mathrm{mm}]}\end{array}$ & $\begin{array}{c}b_{2} \\
{[\mathrm{~mm}]}\end{array}$ & $\begin{array}{c}a_{1 / 2} \\
{[\mathrm{~mm}]}\end{array}$ & $\begin{array}{c}T_{N 2} \\
{[\mathrm{Nm}]}\end{array}$ \\
\hline 10 & 7 & 69 & 9.86 & 30 & 2.28 & 2.25 & 19 & 100 & 259.66 \\
\hline 10 & 8 & 79 & 9.88 & 30 & 2.00 & 2 & 19 & 100 & 260.14 \\
\hline 10 & 9 & 89 & 9.89 & 30 & 1.77 & 1.75 & 19 & 99 & 260.5 \\
\hline 10 & 10 & 99 & 9.90 & 30 & 1.60 & 1.5 & 19 & 95 & 234.71 \\
\hline 10 & 11 & 109 & 9.91 & 30 & 1.45 & 1.5 & 19 & 104 & 306.72 \\
\hline 10 & 12 & 119 & 9.92 & 30 & 1.33 & 1.25 & 19 & 95 & 228.58 \\
\hline 10 & 13 & 129 & 9.92 & 30 & 1.23 & 1.25 & 19 & 103 & 300.61 \\
\hline 10 & 14 & 139 & 9.93 & 30 & 1.14 & 1 & 19 & 90 & 202.7 \\
\hline 10 & 15 & 149 & 9.93 & 30 & 1.06 & 1 & 19 & 95 & 228.96 \\
\hline 10 & 16 & 159 & 9.94 & 30 & 1.00 & 1 & 19 & 101 & 274.87 \\
\hline 10 & 17 & 169 & 9.94 & 30 & 0.94 & 0.9 & 19 & 97 & 242.24 \\
\hline 10 & 18 & 179 & 9.94 & 30 & 0.89 & 0.9 & 19 & 103 & 301.26 \\
\hline 10 & 19 & 189 & 9.95 & 30 & 0.84 & 0.8 & 19 & 97 & 235.84 \\
\hline 10 & 20 & 199 & 9.95 & 30 & 0.80 & 0.8 & 19 & 101 & 255.56 \\
\hline 10 & 21 & 209 & 9.95 & 30 & 0.76 & 0.8 & 19 & 105 & 301.5 \\
\hline 10 & 22 & 219 & 9.95 & 30 & 0.73 & 0.7 & 19 & 97 & 203.23 \\
\hline 10 & 23 & 229 & 9.96 & 30 & 0.69 & 0.7 & 19 & 101 & 236.06 \\
\hline
\end{tabular}

Table 4. Load carrying capacity of gear pairs for different teeth number and module of pinion, but for the same pinion diameter 
Table 5. Load carrying capacity and dimensions of gear pairs for particular values of gear ratio and adopted central distance, for the same module value

\begin{tabular}{|c|c|c|c|c|c|c|c|c|c|c|}
\hline$u_{R 20}$ & $z_{1}$ & $z_{2}$ & $u_{r}$ & $\begin{array}{c}B_{1 / 2} \\
{\left[{ }^{\circ}\right]}\end{array}$ & $\begin{array}{c}m_{\mathrm{n} 1 / 2 \text { stan }} \\
{[\mathrm{mm}]}\end{array}$ & $\begin{array}{c}d_{w 1} \\
{[\mathrm{~mm}]}\end{array}$ & $\begin{array}{c}d_{w 2} \\
{[\mathrm{~mm}]}\end{array}$ & $\begin{array}{c}b_{2} \\
{[\mathrm{~mm}]}\end{array}$ & $\begin{array}{c}a_{1 / 2} \\
{[\mathrm{~mm}]}\end{array}$ & $T_{N 2}[\mathrm{Nm}]$ \\
\hline 10 & 8 & 79 & 9.88 & 30 & 2 & 18.3908 & 181.609 & 19 & 100 & 253.63 \\
\hline 9 & 9 & 80 & 8.89 & 30 & 2 & 20.2247 & 179.775 & 19 & 100 & 275.13 \\
\hline 8 & 10 & 79 & 7.90 & 30 & 2 & 22.4719 & 177.528 & 19 & 100 & 322.57 \\
\hline 7.1 & 11 & 78 & 7.09 & 30 & 2 & 24.7191 & 175.281 & 19 & 100 & 373.59 \\
\hline 6.3 & 12 & 76 & 6.33 & 30 & 2 & 27.2727 & 172.727 & 19 & 100 & 458.8 \\
\hline 5.6 & 13 & 73 & 5.62 & 30 & 2 & 30.2326 & 169.767 & 19 & 100 & 554.72 \\
\hline 5 & 15 & 74 & 4.93 & 30 & 2 & 33.7079 & 166.292 & 19 & 100 & 536.08 \\
\hline 4.5 & 16 & 72 & 4.50 & 30 & 2 & 36.3636 & 163.636 & 19 & 100 & 622.351 \\
\hline 4 & 18 & 71 & 3.94 & 30 & 2 & 40.4494 & 159.551 & 19 & 100 & 623.45 \\
\hline 3.55 & 20 & 70 & 3.50 & 30 & 2 & 44.4444 & 155.556 & 19 & 100 & 599.3 \\
\hline 3.15 & 21 & 66 & 3.14 & 30 & 2 & 48.2759 & 151.724 & 19 & 100 & 703.73 \\
\hline 2.8 & 23 & 64 & 2.78 & 30 & 2 & 52.8736 & 147.126 & 19 & 100 & 696.36 \\
\hline 2.5 & 25 & 63 & 2.52 & 30 & 2 & 56.8182 & 143.182 & 19 & 100 & 697.03 \\
\hline 2.24 & 27 & 61 & 2.26 & 30 & 2 & 61.3636 & 138.636 & 19 & 100 & 681.45 \\
\hline 2 & 29 & 59 & 2.03 & 30 & 2 & 65.9091 & 134.091 & 19 & 100 & 656.52 \\
\hline 1.8 & 31 & 56 & 1.81 & 30 & 2 & 71.2644 & 128.736 & 19 & 100 & 618.63 \\
\hline 1.6 & 34 & 54 & 1.59 & 30 & 2 & 77.2727 & 122.727 & 19 & 100 & 585.74 \\
\hline 1.4 & 36 & 51 & 1.42 & 30 & 2 & 82.7586 & 117.241 & 19 & 100 & 569.11 \\
\hline 1.25 & 39 & 49 & 1.26 & 30 & 2 & 88.6364 & 111.364 & 19 & 100 & 521.28 \\
\hline 1.12 & 41 & 46 & 1.12 & 30 & 2 & 94.2529 & 105.747 & 19 & 100 & 502.44 \\
\hline
\end{tabular}

Notification: The calculation has a certain dissipation of the torque value because of the application of different profile shift coefficients, and this dissipation is neglected in this case.

If the pinion diameter and the gear ratio are defined, the diameter of the driven gear and the central distance are defined (Fig.4 and Table 4) $[9,11]$ :

$$
\begin{gathered}
d_{2}=u_{1 / 2} d_{1} \\
a_{1 / 2}=\frac{m_{n 1 / 2}}{\cos \beta_{1 / 2}} \cdot \frac{z_{1}+z_{2}}{2} \cdot \frac{\cos \alpha_{t}}{\cos \alpha_{w t}}
\end{gathered}
$$

where:

$\alpha_{t}-$ transverse pressure angle.

$\alpha_{w t}-$ transverse working pressure angle.

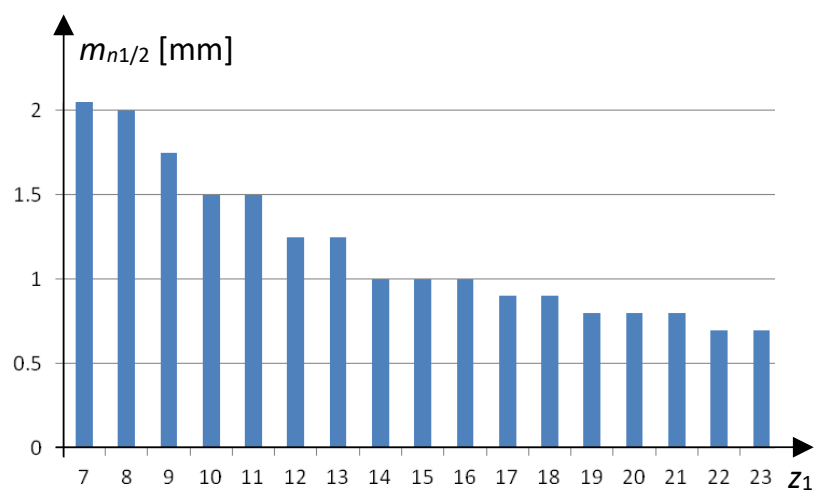

Fig.5. The values of required modules for the particular teeth number of pinion for approximately the same central distance $\mathrm{a} \approx 100 \mathrm{~mm}$ and the gear ratio $\mathrm{u} \approx 10$
Based on the previous calculation (Table 4), it is evident that with the reduction of the module value, for the same central distance, the teeth number of gear increases, while the value of load capacity remains almost the same. In this case, the module can be reduced from $2 \mathrm{~mm}$ to $0.7 \mathrm{~mm}$ or less (Fig.5). of course, there is no justification for the application of small modules, since the teeth are smaller then and thus their load capacity (Fig.6).

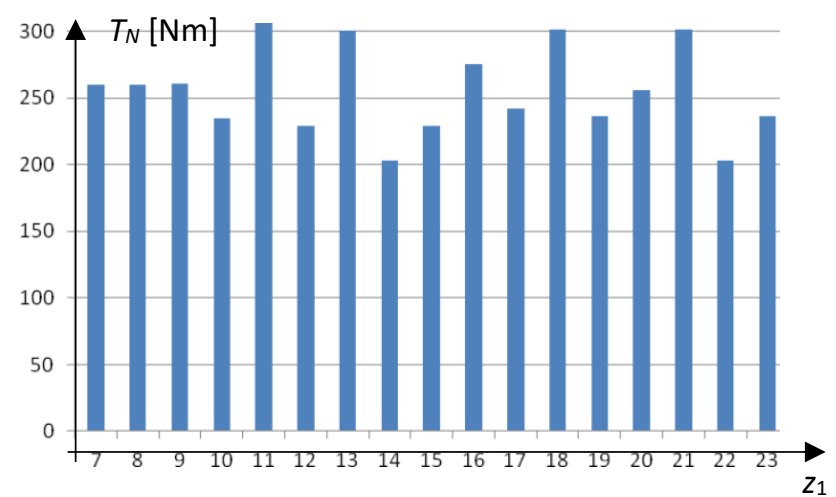

Fig.6. Load carrying capacities obtained for different teeth number of pinion for approximately the same central distance $a \approx 100 \mathrm{~mm}$ and the minimum required module value

If it is adopted standard module value of $2 \mathrm{~mm}$ for gear pair with gear ratio according standard row R20 (Table 5), it can be concluded that the load 
capacity of the gear pairs with smaller gear ratio increases, which is logical since the pinion diameter has larger dimension (Fig.7).

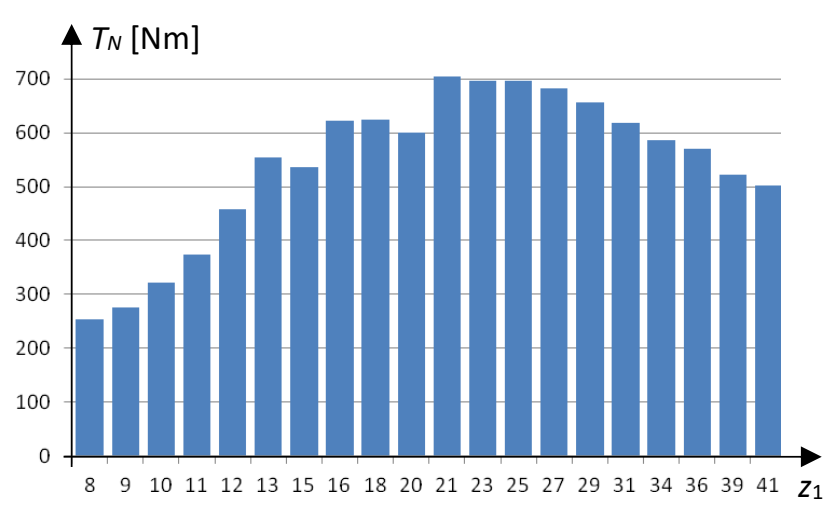

Fig.7. Load carrying capacities obtained for different teeth number of pinion for the same central distance

$\mathrm{a}=100 \mathrm{~mm}$ and adopted module $\mathrm{m}_{\mathrm{n}}=2 \mathrm{~mm}$

If the values of modules for gear pairs with lower gear ratio would be increased, it would significantly increase its load capacity (Fig.7). However, it is not necessary, since it would require more tools during production, and also this increased load capacity could not be used, because with a large number of gear ratios this capacity is smaller and it is no reasonable to install other stronger components (shafts, bearings, keys, etc.) because they could not be used rationally. For very low gear ratios, the load capacity of gear pairs is not decreased, while the output torque of the gearbox is decreased due to reduced load capacity of the bearings at high speeds.

If this analysis of load carrying capacities is carried out for all gear ratio, it can be seen that with the change of the module there is a significant change in the load capacity of the gear pairs (Fig.8 and 9). The great difference in load capacity is not justified in this case, because stronger bearings, shafts, keys and other components should be installed, but they could not be used in all gear ratios.

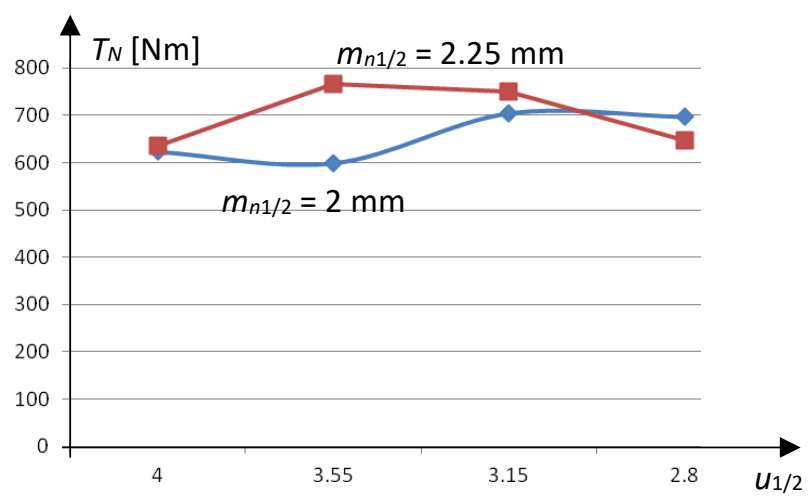

Fig.8. Comparison of load capacities obtained for different gear ratio for the same central distance $\mathrm{a}=100 \mathrm{~mm}$ and two module values

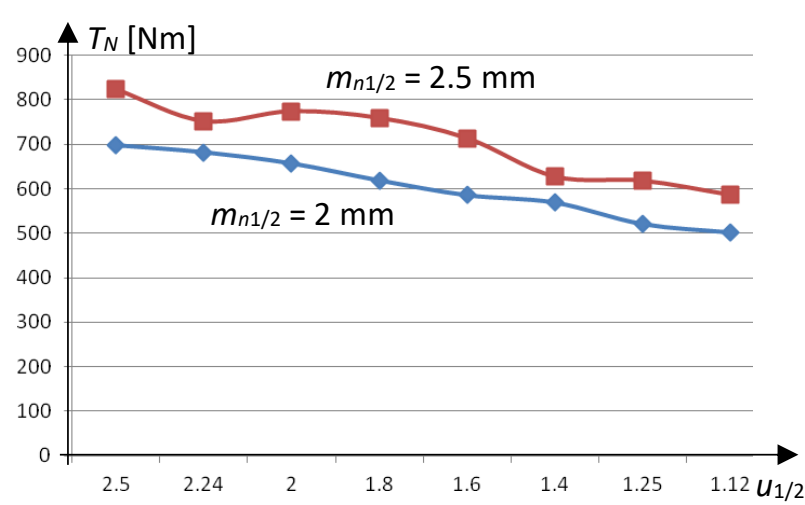

Fig. 9. Comparison of load capacities obtained for different gear ratio for the same central distance $\mathrm{a}=$ $100 \mathrm{~mm}$ and two module values

\section{CONCLUSION}

This paper defines the way of preliminary calculation of gear pair inside the single-stage gearbox. Also, it defines a way for determination of gear ratio, teeth number and module values. On the basis of the carried out preliminary calculation of a gear pair in single-stage gear reducer with axial height of $100 \mathrm{~mm}$, maximal nominal torque $200 \mathrm{Nm}$ and the highest gear ratio 10, the minimal pinion diameter is $18.43 \mathrm{~mm}$ for the helical angle of $30^{\circ}$ and different pinion teeth numbers $(7,8,9,10$, $11,12,13,14,15,16,17,18,19,20,21,22,23)$. The actual value of the torque at the output is $200-300$ $\mathrm{Nm}$ which indicates that the teeth number and the module have no major impact on the load carrying capacity of the gearbox. However, if the gear ratio values and module values are varied, it can be concluded that the change of load capacity is significant. Nevertheless, using the large module values is often not justified, since it provides great load capacity for small gear ratio. But the problem is that other gearbox components should carry this large load capacity which requires stronger and more expensive gearbox components.

In the final selection of the module value, it must be have in mind that larger modules provide greater load capacity, but also increase the production costs of the gearbox. Since the final load carrying capacity of the gearbox is also limited by the capacity of the other components within the gearbox, it can be concluded it is not justifiable to apply very large and different values of modules. In that case production of gearbox requires more different tools, more tools installation and set up, more complex control, etc. The aim of this paper is to point out the justification of a simple approach to the selection of the basic gears parameters and the benefits that are achieved. 


\section{REFERENCES}

[1] S. Kuzmanović, Universal Gear Reducers with Cylindrical Gears (in Serbian). University of Novi Sad, Faculty of Technical Sciences, Novi Sad, 2009.

[2] N. Marjanovic, B. Isailovic, V. Marjanovic, Z. Milojevic, M. Blagojevic, M. Bojic, A practical approach to the optimization of gear trains with spur gears. Mechanism and Machine Theory, 53 (-), 2012: 1-16.

https://doi.org/10.1016/j.mechmachtheory.2012.02. $\underline{004}$

[3] M. Rackov, Conceptions of Development of Universal Gear Reducers (Ph.D. thesis in Serbian). University of Novi Sad, Faculty of Technical Sciences, 2013.

[4] Catalog: DRN Gearmotors. SEW EURODRIVE, (IE3) Edition 11/2015, 2133189/EN.

[5] Catalog: NORD Driversystems G1000, constant speeds, www.nord.com.

[6] Catalog: motox GEARED MOTORS, D87.1.2007, SIEMENS.
[7] Catalog: L-force, Getriebemotoren. Lenze, de 02/2016.

[8] Catalog: E04 - Coaxial Gear Reducers and Gearmotors. Rossi Habasit Group, Edition December 2015, 4002BRO.ECO-en 1210 HQM.

[9] S. Kuzmanović, Machine Elements (in Serbian), University of Novi Sad, Faculty of Technical Sciences, Novi Sad, 2016.

[10] N. Marjanovic, B. Ivkovic, M. Blagojevic, B. Stojanovic, Experimental determination of Friction coefficient at Gear drives. Journal of the Balkan Tribological Association, 16 (4), 2010: 517-526.

[11] N. Marjanovic, N. Kostic, M. Blagojevic, V. Marjanovic, B. Isailovic, Automated Gear Train Modeling in CAD Environment. Proceedings of the International conference "DEMI 2013", 30" May - $1^{\text {th }}$ June 2013, Banja Luka, Bosnia and Herzegovina, pp.107-110.

The shorter version of this research was presented at the "8nd International Scientific Conference IRMES 2017", 7 - 9 September 2017, Trebinje, Bosnia and Hercegovina. 